Ronald D. Brown

Chemistry Department, Monash University

Clayton, Victoria, 3168,

Australia.

With the discovery of the first polyatomic molecules, $\mathrm{NH}_{3}, \mathrm{H}_{2} \mathrm{O}$ and $\mathrm{H}_{2} \mathrm{CO}$ in $1968 / 9^{1}$ there was immediate speculation as to how far biological chemical evolution - from atoms to small carbon compounds of biological significance - could have occurred in the Galaxy. There was also potential conflict with the canonical scientific view of the origin of life, traceable to the production of simple bio-molecules from the influence of energetic atmospheric events on the simple gaseous mixture $\left(\mathrm{CH}_{4}, \mathrm{H}_{2}, \mathrm{H}_{2} \mathrm{O}\right.$ and $\left.\mathrm{NH}_{3}\right)$ presumed to compose the atmosphere of the very young Earth.

Subsequent discoveries have increased the list of identified interstellar molecules in dark nebulae to about 60 (see Table 1) and have also hardened the belief of astronomers that dark nebulae are sites in which formation of new stars and planetary systems occurs. In addition there has been a steady development of the theory of galactochemistry, starting in the early 1970's, explaining the chemical generation of polyatomic interstellar molecules from their atomic precursors $^{2}$. I may illustrate the current state of the art with results of calculations by my own group at Monash ${ }^{3}$, showing the predicted time evolution of abundances of species (Fig. 1) and a comparison with best observational estimates of the composition of dark nebulae of age in the vicinity of $10^{7} \mathrm{yr}$ (see Table 2). The agreement is surprisingly good in view of the very simple model adopted for molecular clouds.*

*It is gratifying that a major anomaly, namely that the predicted fractional abundance of $\mathrm{CO}^{+}$in ori $\mathrm{A}$ is about $10^{-14}$, which appeared to be in conflict with observations ${ }^{4}$ indicating an abundance of $10^{-10}$ to $10^{-12}$, has been resolved because it seems that the line attributed to $\mathrm{CO}^{+}$is actually a line of methanol. It is also gratifying that our galactochemical model (Fig. 2) predicted a fractional abundance of the new oxide of carbon, $\mathrm{C}_{3} \mathrm{O}$ in $\mathrm{TMCl}$ of around $10^{-10}$, in excellent agreement with our subsequent observations ${ }^{5}$, which imply $x\left(C_{3} O\right)=9 \pm 3 \times 10^{-11}$. 
Table 1

\section{INTERSTELLAR MOLECULES}

$\begin{array}{lllll}\mathrm{H}_{2} & \mathrm{CO} & \mathrm{H}_{2} \mathrm{CNH} & \mathrm{CC} & \text { NaOH? } \\ \mathrm{OH} & & \mathrm{H}_{3} \mathrm{CNH}_{2} & \mathrm{CS} \\ \mathrm{CH} & \mathrm{OCS} & \mathrm{HN}_{2}^{+} & \text {SiS } \\ \mathrm{CH}^{+} & \mathrm{NO} & \mathrm{NH}_{3} & \text { NS } \\ \mathrm{H}_{2} \mathrm{O} & \text { HNO? } & \mathrm{CH}_{4}^{*} & \text { SO } \\ \mathrm{H}_{2} \mathrm{~S} & \text { SiO } & & \mathrm{SO}_{2}\end{array}$

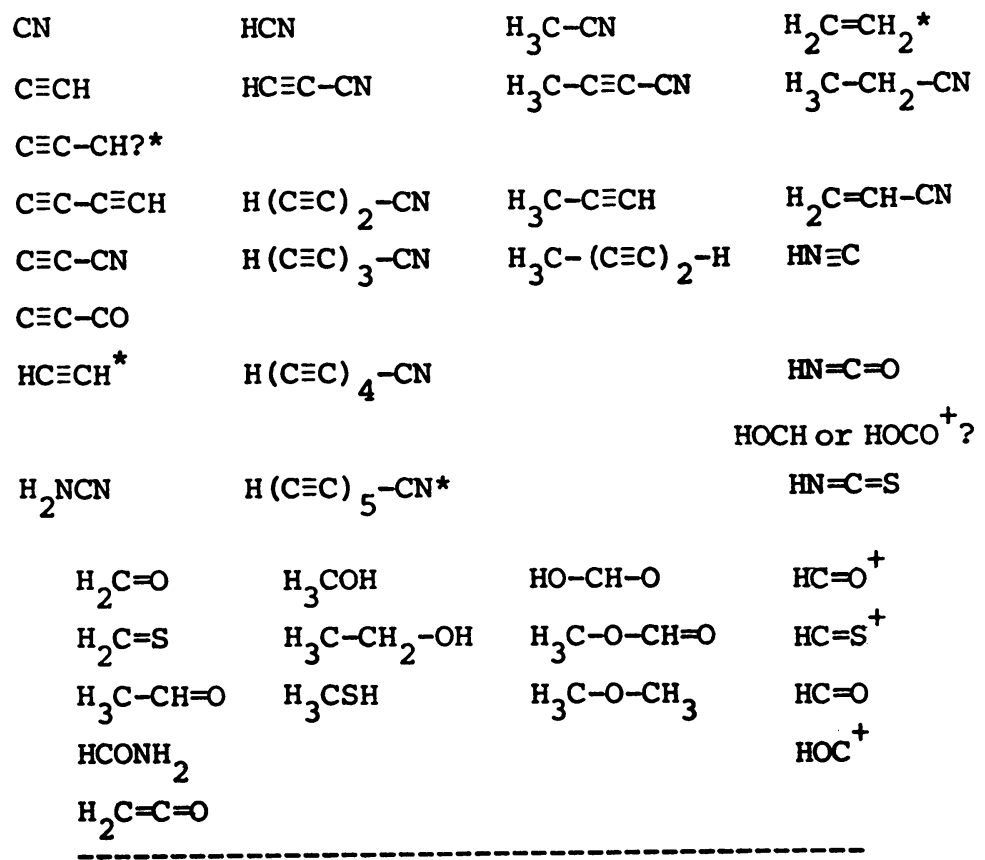

* Detected only in the envelope around the evolved star IRC $=10216$.

${ }^{3}$ Claimed but not yet confirmed. 
Figure 1(a)

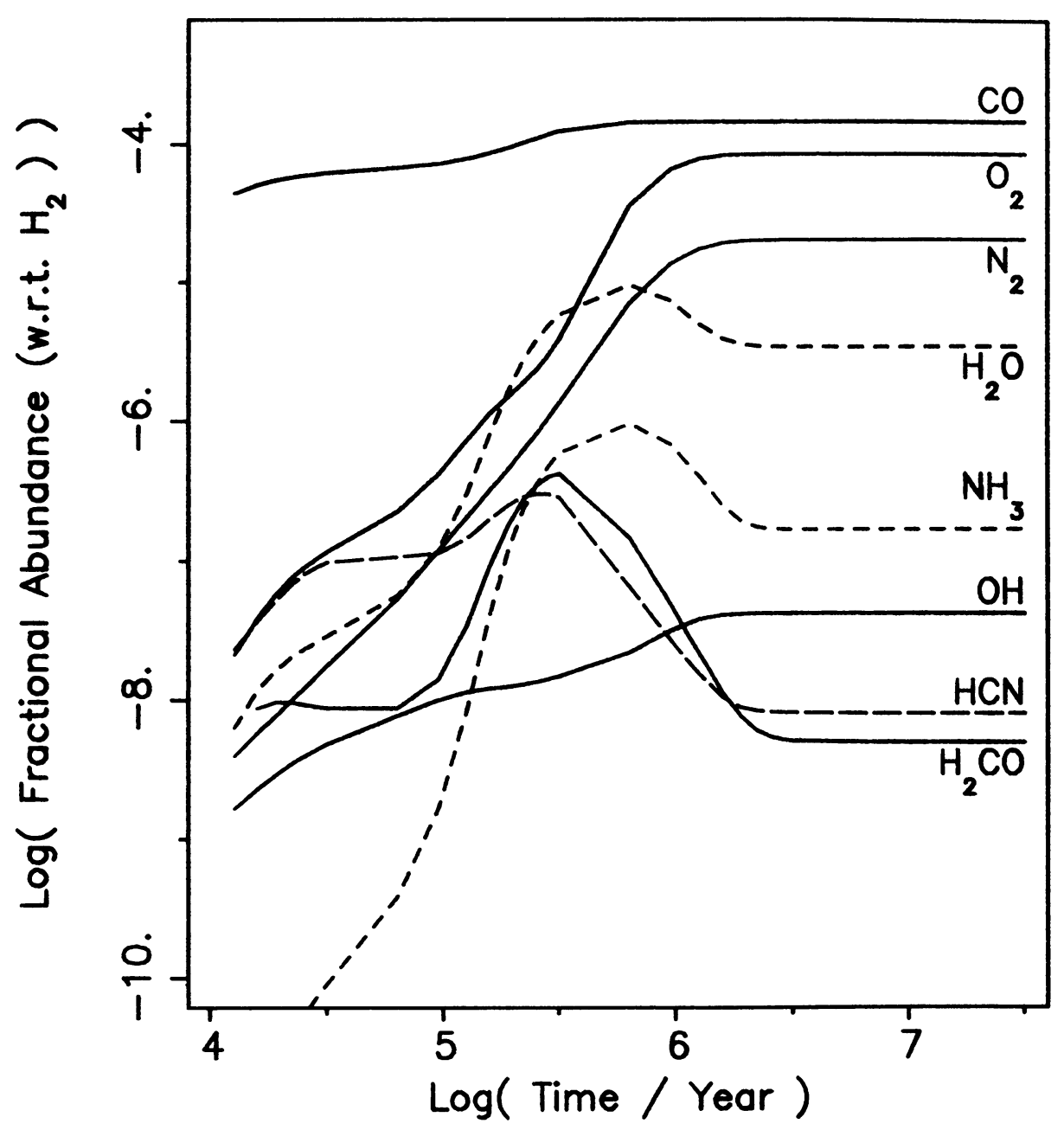

Figure 1

Variation of Predicted Molecular Abundance with Age of Molecular Cloud (Brown \& Rice, unpublished). Some curves are dotted for clarity in respect of crossings. (a) small species; (b) $\mathrm{C}_{3} \mathrm{O}$ and related species; (c) glycinonitrile and related species, (1) with, (2) without dotted pathways shown in Figure 4 . 
Figure $1(b)$

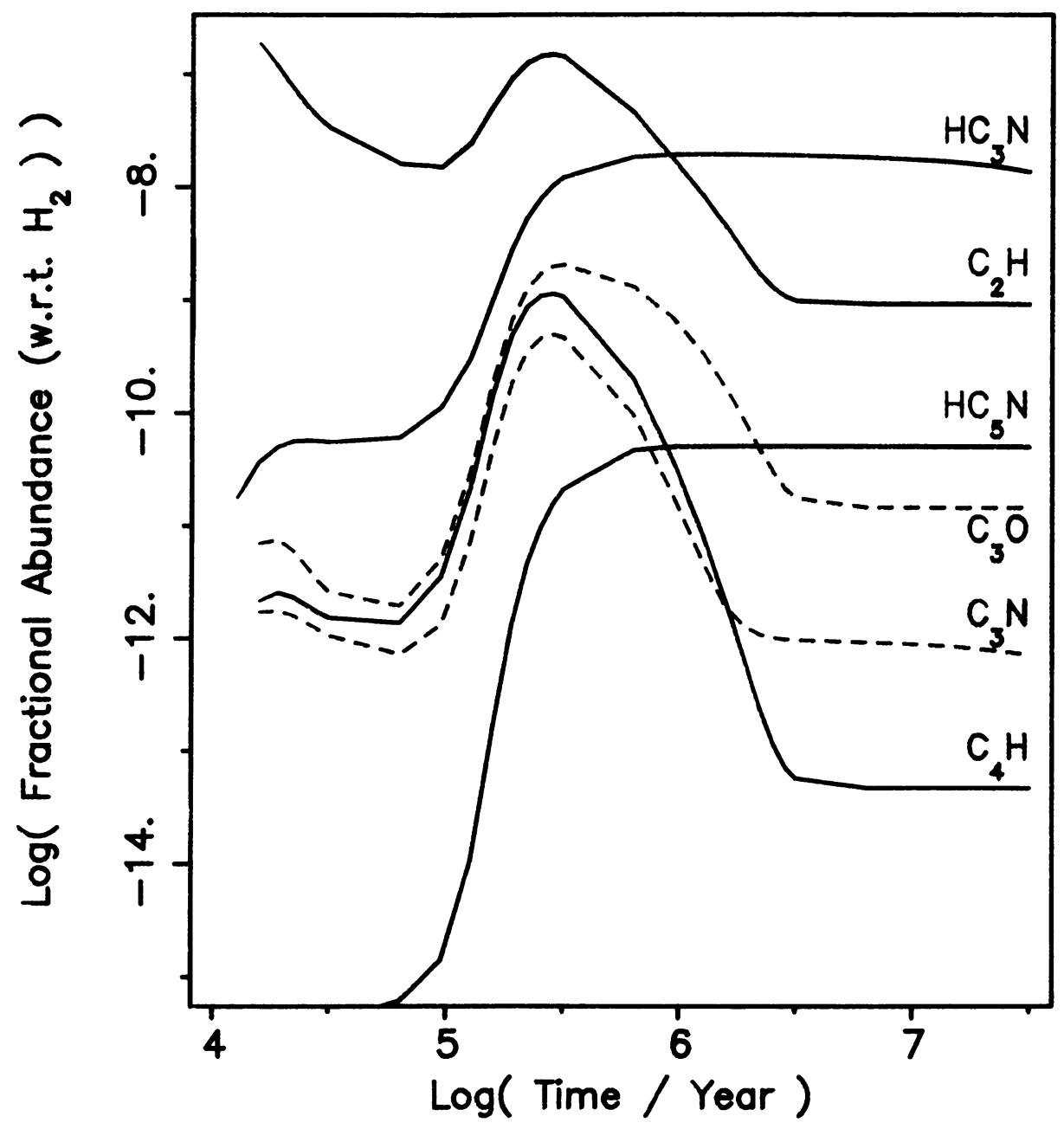


Figure 1(c)

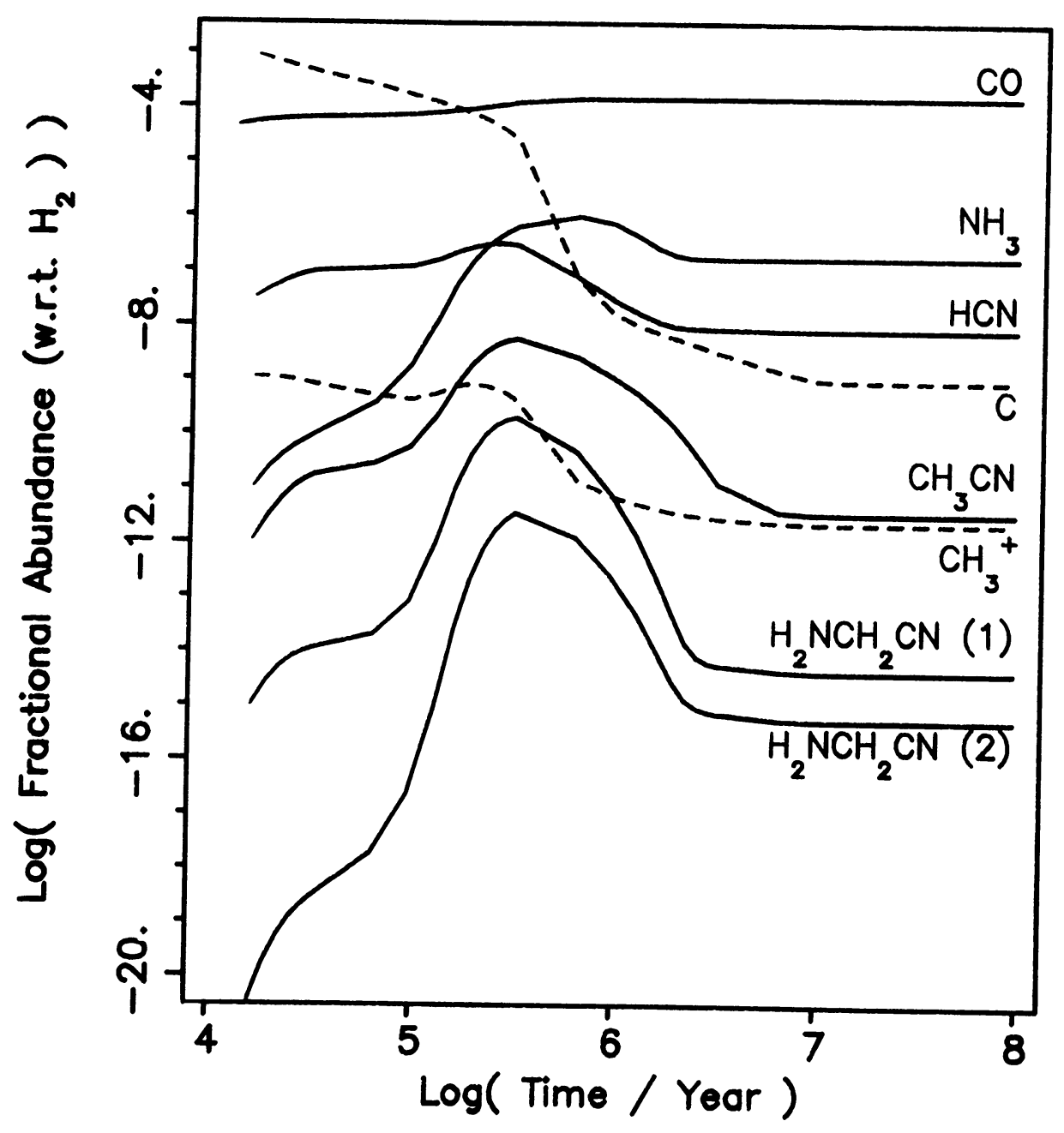


Table 2

\section{COMPARISON OF BROWN AND RICE MODEL}

\section{WITH OBSERVED ABUNDANCES IN COOL CLOUDS}

$$
\mathrm{T}=10 \text { To } \underset{\text { Low Metals }}{20 \mathrm{~K}: \mathrm{n}\left(\mathrm{H}_{2}\right)=10^{4} \mathrm{~cm}^{-3}}
$$

\begin{tabular}{|c|c|c|}
\hline Species & $\begin{array}{c}\mathrm{Ca1c} \cdot\left(10^{8} \mathrm{yr}\right) \\
-\log (\mathrm{X})\end{array}$ & $\begin{array}{l}\text { Obs. } \\
\text {-Log(X) }\end{array}$ \\
\hline $\mathrm{CN}$ & 8.4 to 8.2 & 9.0 to 7.5 \\
\hline $\mathrm{H}_{2} \mathrm{CO}$ & 8.4 & 8.8 to 8.0 \\
\hline $\mathrm{HCN}$ & 8.3 to 8.1 & 7.9 to 7.7 \\
\hline $\mathrm{OH}$ & 7.4 to 7.2 & 7.2 to 6.5 \\
\hline $\mathrm{N}_{2} \mathrm{H}^{+}$ & 9.2 to 9.1 & 9.0 \\
\hline $\mathrm{HCO}^{+}$ & 7.9 to 7.7 & $8 \cdot 1$ \\
\hline $\mathrm{C}_{2} \mathrm{H}$ & 8.7 & 8.1 \\
\hline $\mathrm{NH}_{3}$ & 6.9 to 6.8 & 7.7 to 7.0 \\
\hline $\mathrm{CO}$ & 3.8 & 3.9 to 4.2 \\
\hline $\mathrm{CH}$ & 9.3 to 9.1 & 7.7 \\
\hline
\end{tabular}




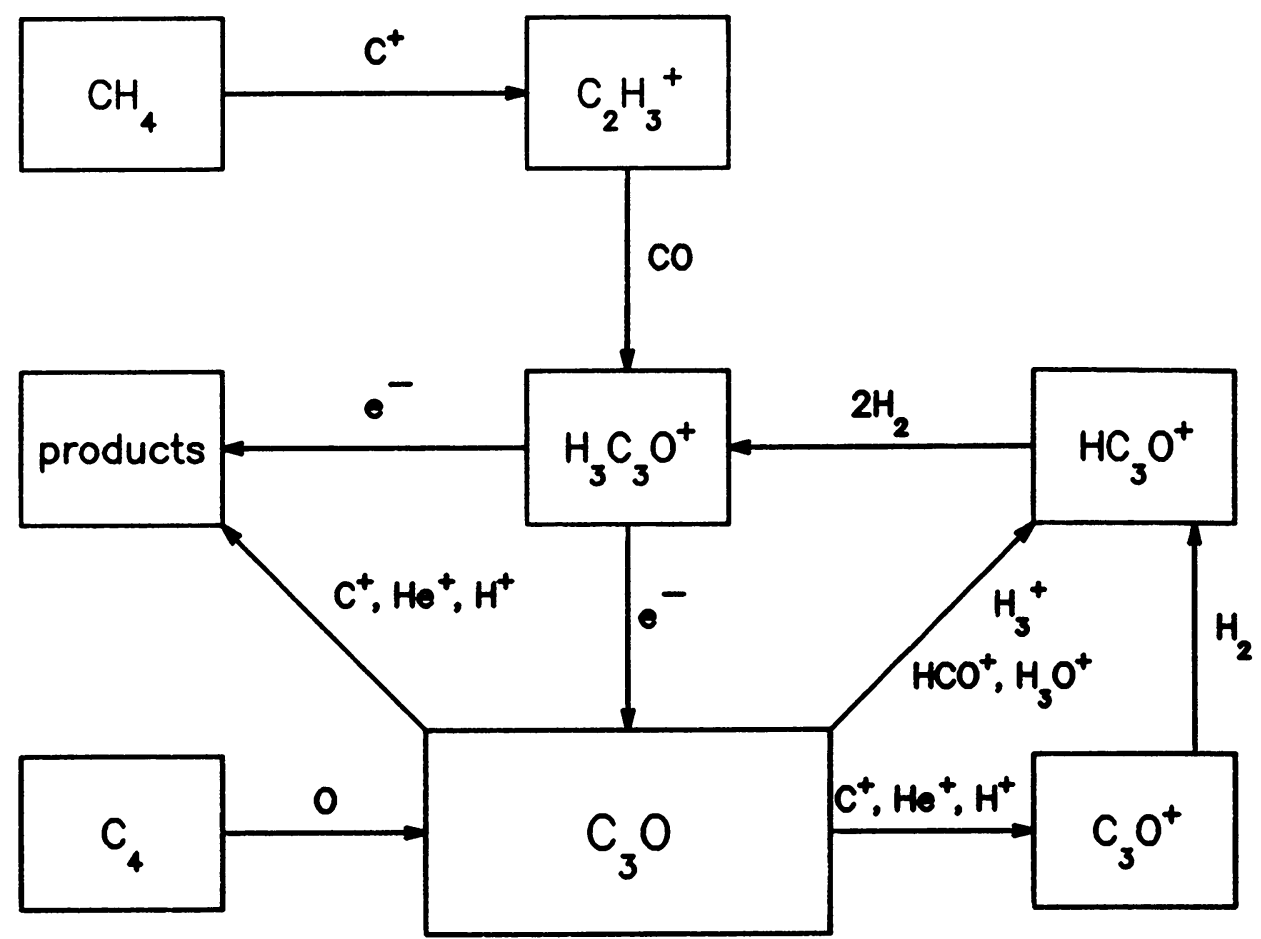

Figure 2 Formation channels for $\mathrm{C}_{3} \mathrm{O}$ in Molecular Clouds. 
It is therefore not unreasonable to explore on the basis of our current galactochemical model some questions that would relate to the rate of generation of biologically interesting interstellar molecules and their possible connection with the origin of life. We could discuss at some length the pathways by which biologically significant materials might be constructed from various interstellar molecules - sugars from formaldehyde, pyrimidines and purines (the alphabet of the genetic code) from HCN or isocyanic acid and cyanoacetylene, and so on ${ }^{6}$. However I shall confine myself to two aspects of one particular kind of interstellar molecule of biological importance, namely aminoacids, the building blocks of proteins. The two aspects are:

(a) what progress has occured in trying to detect aminoacids in molecular clouds?

(b) what has galactochemistry to say about gas-phase production of aminoacids in molecular clouds?

Let us deal first with (a). There have been some extensive interstellar searches for the simplest aminoacid - glycine, $\mathrm{H}_{2} \mathrm{~N} \cdot \mathrm{CH}_{2} \cdot \mathrm{CO}_{2} \mathrm{H}$ - all so far unsuccessfu1. The search is complicated by the fact that there are two distinct conformers of glycine of lower energy than the rest (see Fig. 3). The search by our group ${ }^{7}$ was for conformer (4) and included the sources $\mathrm{Sgr}$ B2 and Ori A as well as some dark clouds. It yielded estimated upper limits of column densities for $\mathrm{Sgr}$ B2 of $10^{14} \mathrm{~cm}^{-2}$ and, for the dark clouds, $10^{12} \mathrm{~cm}^{-2}$ corresponding to fractional abundances of about $10^{-9}$ and $10^{-10}$ respectively (see Table 3). The first search was followed by a search for conformer (3) which gave an upper limit of column density in $\mathrm{Sgr} B 2$ of $10^{15} \mathrm{~cm}^{-2}$.

Searching goes on at Arecibo ${ }^{9}$ for both conformers, but with no positive success so far although the upper limits for column densities in sources such as W49, W51, and in Comet Encke, have been reduced to about $10^{12} \mathrm{~cm}^{-2}$.

Turning now to (b), let us consider how aminoacids, or their chemically close relatives, might be formed by gas-phase reactions in molecular clouds. We can conveniently restrict consideration to glycine. Among the identified interstellar molecules the most closely related molecules are $\mathrm{CH}_{3} \mathrm{CN}$ and $\mathrm{CH}_{3} \mathrm{NH}_{2}$. Can we envisage further processes that might lead to glycine?

In a formal sense we can write down a reaction between two known interstellar species:

$$
\mathrm{CH}_{3} \cdot \mathrm{NH}_{2}+\mathrm{H} \cdot \mathrm{CO}_{2} \mathrm{H} \rightarrow \mathrm{H}_{2} \mathrm{~N} \cdot \mathrm{CH}_{2} \cdot \mathrm{CO}_{2} \mathrm{H}+\mathrm{H}_{2}
$$

but such a process is chemically exceedingly unlikely and in any case both reactants are of very low abundance in molecular clouds. Reactions involving related ions of these species likewise can be ruled out on grounds of exceedingly low concentrations and that they would very likely yield other products $\left(\mathrm{H} \cdot \mathrm{CO} \cdot \mathrm{NH} \cdot \mathrm{CH}_{3}+\mathrm{H}_{2} \mathrm{O}\right.$ or protonated a1ternatives). 


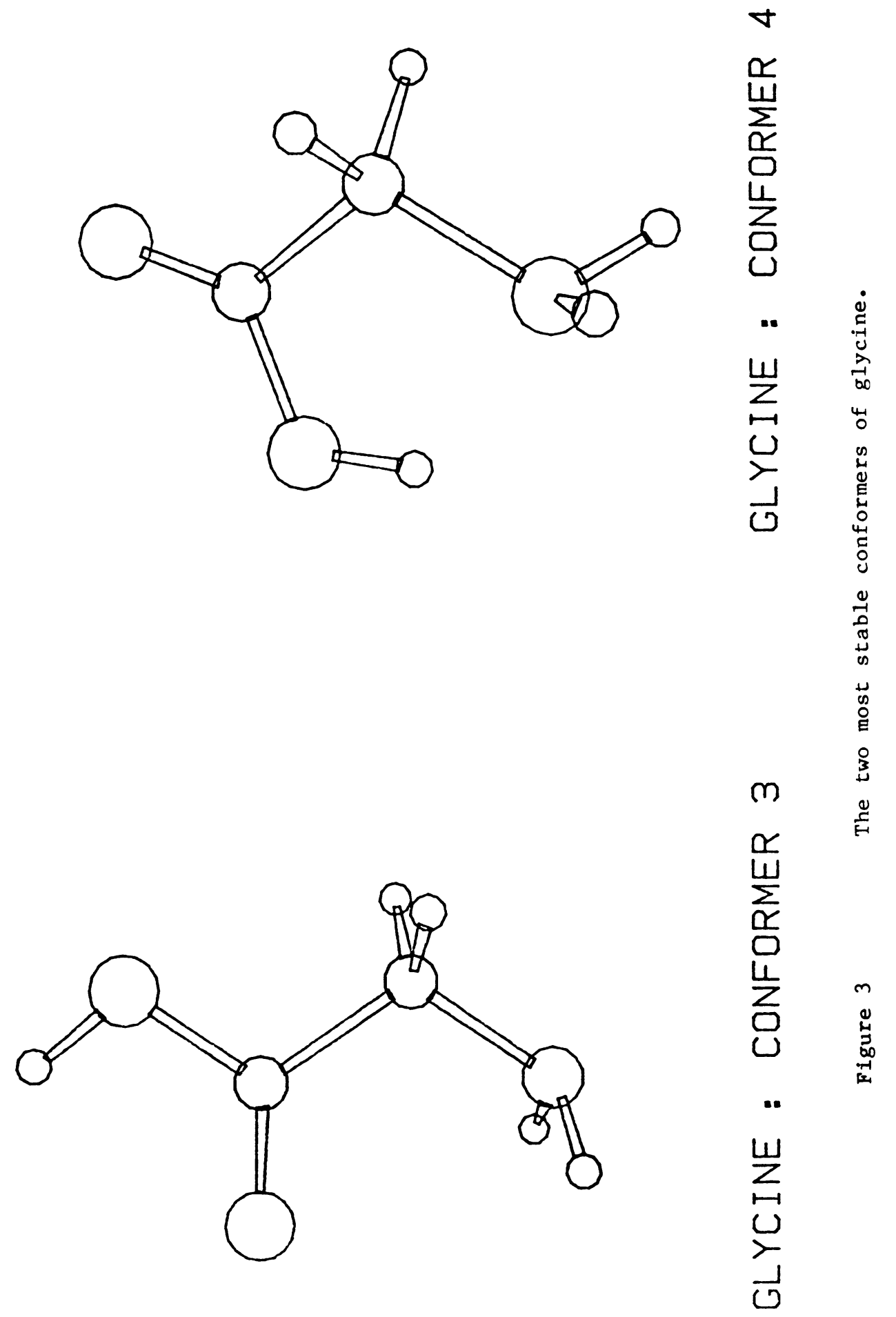


Table 3

GLYCINE (4) SEARCH

Upper limits for observed glycine column density and fractional abundance.
Assumed Hydrogen column density.

$\mathrm{NL}\left(\mathrm{cm}^{-2}\right)$

Source

$\mathrm{NL}\left(\mathrm{cm}^{-2}\right)$

$\mathrm{X}$

NL $\left(\mathrm{cm}^{-2}\right)$

\begin{tabular}{lllc} 
Sgr B2 $(\mathrm{OH})$ & $7 \times 10^{13}$ & $7 \times 10^{-10}$ & $10^{23}-10^{24 \mathrm{a}}$ \\
Ori A(OH) & $3 \times 10^{13}$ & $7 \times 10^{-10}$ & $4 \times 10^{23}-4 \times 10^{24 \mathrm{~b}}$ \\
DR21(OH) & $6 \times 10^{13}$ & $1.5 \times 10^{-9}$ & $4 \times 10^{23}-4 \times 10^{24 \mathrm{~b}}$ \\
TMC1 & $2 \times 10^{12}$ & $2 \times 10^{-10}$ & $\sim 10^{24}$ \\
NGC2264 & $4 \times 10^{14}$ & $1 \times 10^{-7}$ & $4 \times 10^{21}-4 \times 10^{22} \mathrm{~b}$ \\
W51 & $4 \times 10^{14}$ & $5 \times 10^{-9}$ & $8 \times 10^{22}-8 \times 10^{23 \mathrm{~b}}$ \\
NGC7538 & $4 \times 10^{14}$ & $1 \times 10^{-8}$ & $3 \times 10^{22}-3 \times 10^{23} \mathrm{~b}$ \\
W3(OH) & $2 \times 10^{14}$ & $2 \times 10^{-8}$ & $10^{22}-10^{23 \mathrm{~b}}$ \\
L134N & $3 \times 10^{12}$ & $2 \times 10^{-10}$ & $1.3 \times 10^{22 \mathrm{c}}$ \\
\hline
\end{tabular}

${ }^{a}$ Scoville et a1., Ap. J., 201, 352-365 (1975).

$\mathrm{b}_{\text {Wilson et }}$ al., Ap. J., 191, 357-374 (1974).

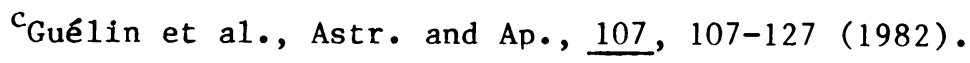


However if we consider $\mathrm{CH}_{3} \mathrm{CN}$ and its probable interstellar precursor $\mathrm{CH}_{3} \mathrm{CNH}^{+}$[produced via the radiative association $\mathrm{CH}_{3}^{+}+\mathrm{HCN} \rightarrow$ $\left.\mathrm{CH}_{3} \mathrm{CNH}^{+}+\mathrm{h} \nu\right\}$ then we might envisage the possible step:

$$
\mathrm{CH}_{3} \mathrm{CNH}^{+}+\mathrm{NH}_{3} \rightarrow \mathrm{H}_{3} \mathrm{~N}^{+} \cdot \mathrm{CH}_{2} \mathrm{CN}+\mathrm{H}_{2}
$$

which could be followed by

$$
\mathrm{H}_{3} \mathrm{~N} \cdot \mathrm{CH}_{2} \cdot \mathrm{CH}^{+}+\mathrm{e} \rightarrow \mathrm{H}_{2} \mathrm{NCH}_{2} \mathrm{CN}+\mathrm{H} \cdot
$$

This seems a plausible pathway to glycinonitrile $\left(\mathrm{H}_{2} \mathrm{~N} \cdot \mathrm{CH}_{2} \cdot \mathrm{CN}\right)$.

A competing destruction channe1 is -

$$
\mathrm{CH}_{3} \mathrm{CNH}^{+}+\mathrm{e} \rightarrow \mathrm{CH}_{3} \mathrm{CN}+\mathrm{H} \text {. }
$$

An alternative pathway is:

$$
\begin{gathered}
\mathrm{CH}_{3}^{+}+\mathrm{NH}_{3} \rightarrow \mathrm{CH}_{2} \mathrm{NH}_{2}^{+}+\mathrm{H}_{2} \\
\mathrm{CH}_{2} \mathrm{NH}_{2}^{+}+\mathrm{HCN} \rightarrow \mathrm{H}_{2} \mathrm{NCH}_{2} \mathrm{CNH}^{+}+\mathrm{hv}
\end{gathered}
$$

The dissociative electron recombination reaction for $\mathrm{H}_{3} \mathrm{~N} \cdot \mathrm{CH}_{2} \mathrm{CN}^{+}$ might have branching channels to some other products and so not give a high yield of glycinonitrile. But overa11, crude calculations(see Fig. 4) imply that a reasonable rate of glycinonitrile production is feasible and that fractional abundances could at times become as high as $10^{-10}$.

A previously unpublished search for the $22_{11}-2_{12}$ line of glycinonitrile at Parkes (1974, Apri1) 10 gave an upper limit for the column density in Sgr B2 of $1 \times 10^{17}$, corresponding to a fractional abundance of about $\mathrm{X}<10^{-7}$.

We can therefore see ways in which a close relative of glycine would be found in molecular clouds. It is not too difficult to discuss pathways to nitriles of other aminoacids, e.g. alaninonitrile, from ethyl cyanide. But the simplest case of glycinonitrile illustrates the possible pathway to proteins and primitive life.

We come now to the question of possible survival of interstellar molecules during the formation of planetary systems by collapse of molecular clouds. Contemporary evidence is provided by studies of meteorites and perhaps soon by studies of comets. This aspect of the story is covered in Professor Ponnamperuma's presentation 11 . I will content myself with the comment that the material in $\mathrm{Cl}$ type carbonaceous chondrites was at no stage subjected to temperatures above about $90 \mathrm{C}^{12}$ and therefore the larger known interstellar molecules, and such species as glycinonitrile, could have survived. The relatively heavy meteoritic falls that occurred in the early history of bodies of the inner Solar System ${ }^{13}$ would have brought such material down to the already cooled surface of the young Earth. 


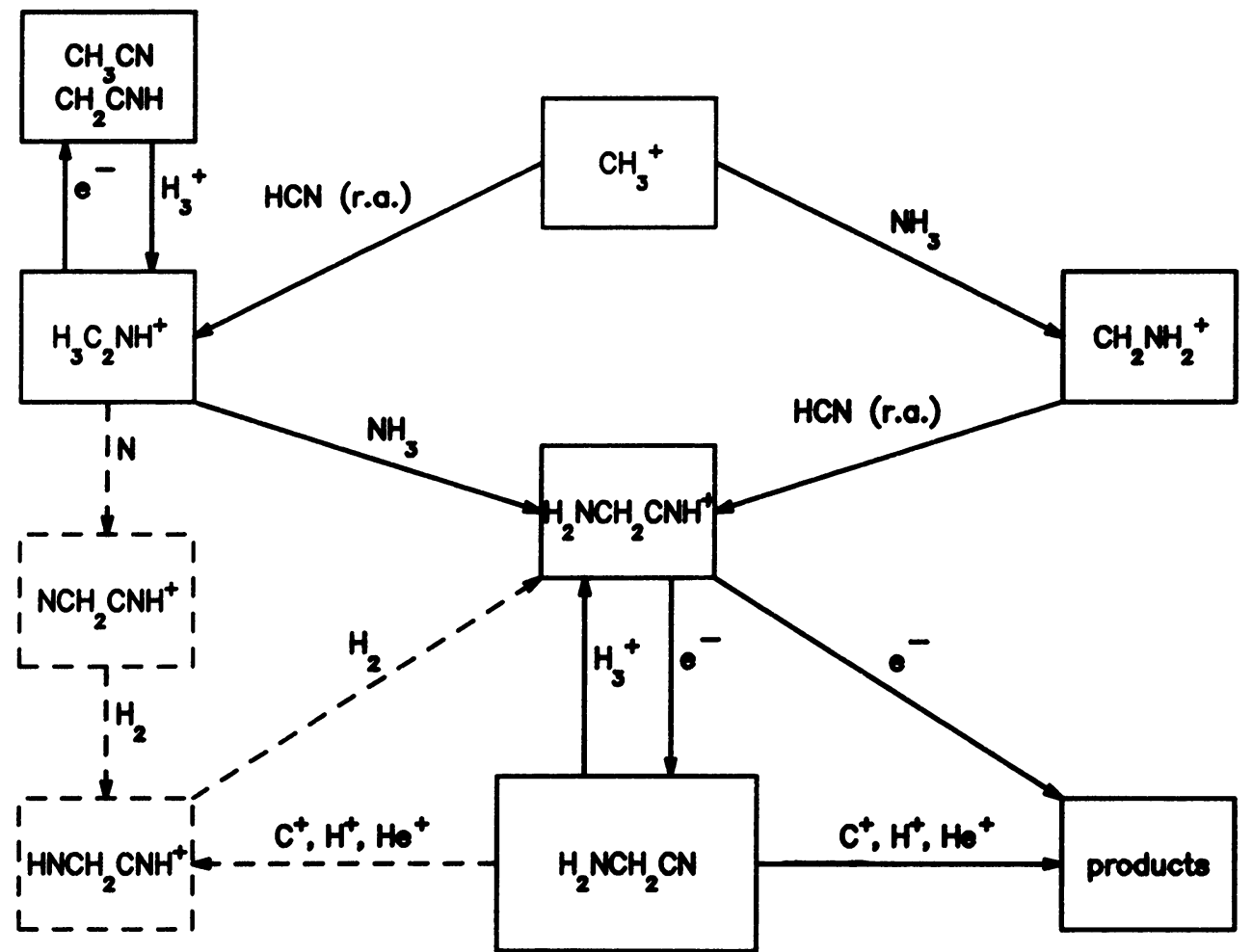

Figure 4

Formation channe1s for Glycinonitrile. Radiative associations are labelled ( $\left.\mathrm{r}_{\cdot} \mathrm{a}_{\bullet}\right)$. Predicted relative abundances of glycinonitrile are: (a) peak

( $3 \times 10^{5}$ yr) $2 \times 10^{-10}$, final $\left(10^{8}\right.$ yr) $4 \times 10^{-15}$;

(b) with dotted pathways omitted, peak $3 \times 10^{-12}$, final $5 \times 10^{-16}$. 
We therefore have to consider whether some of the prebiotic chemicals on the surface of the early Earth could have come in this way from molecular clouds. Other processes, such as the Fischer-Tropsch syntheses that Anders and the Chicago group particularly have emphasised as accompanyng meteoritic and planetary condensation ${ }^{12}$, or the production of prebiotic molecules by energetic processes in the atmosphere of the young $\operatorname{Earth}^{6}$, perhaps also contributed to the chemical menagerie that is widely presumed to precede the evoluton of the first crude metabolising and reproducing system.

It is inappropriate to pursue here the question of the later stages of prebiotic chemical evolution and the earliest forms of life on Earth. But it is important to remember that the interest in aminoacids relates to their condensation to produce polypeptides - important biopolymers. However it is known 14 that glycinonitrile when heated with kaolin in the presence of acid can produce simple polypeptides. It is therefore feasible to consider possible chemical ancestry of 1 ife to pass through interstellar aminoacid nitriles rather than the acids themselves. We should not take for granted that aminoacids are necessarily more important than related types of molecules such as their nitriles in the history of chemical evolution.

We now have a reasonable understanding of interstellar molecules and their relevant galactochemistry even if some aspects, such as the precise role of grain reactions, or the cross-sections for some reaction channe1s, are not yet settled. This enables us to say that it seems feasible that the chemical ancestry of 1ife on Earth goes back to the parental molecular cloud. If so then similar processes of planetary formation elsewhere in the universe may have led to the evolution of life on other planets. There are many imponderables to be resolved by future work on interstellar molecules as well as other areas of the origin of life. Perhaps one day we shall know all the answers! 


\section{REFERENCES}

1. Cheung, A.C., Rank. D.M., Townes, C.H., Thornton, D.D. and We1ch, W.J., Phys. Rev. Lett., 211701 (1968).

Cheung, A.C. Rank, D.M., Townes, C.H. Thornton, D.D. and We1ch, W.J., Nature (Lond), 221, 626 (1969).

Synder, L.E. Buhl, D., Zuckerman, B. and Palmer, P., Phys. Rev.

Lett., 22, 679 (1969).

2. Solomon, P.M. and Klemperer, W., Astrophys. J., 178, 389-421

(1972).

Herbst, E., and Klemperer, W., Astrophys. J., 185, 505-533

(1973).

Aannestad, P.A., Astrophys. J. Supp1., 25, 205-222 (1973),

Watson, W.D., Astrophys. J., 188, 35-42 (1974).

Allen, M. and Robinson, G.W., Astrophys. J., 207, 745-757 (1976).

Black, J.H. and Dalgarno, A., Astrophys. J. Supp1., 34, 405-423

(1977).

Mitche11, G.F., Ginszburg, J.L. and Kuntz, P.J. Astrophys. J.

Supp1.,

38, 39-68 (1978),

Iglesias, E., Astrophys. J, 218, 697-715 (1977).

Gerola, H. and Glassgold, A.E., Astrophys. J. Supp1, 37, 1-25

(1978),

Prasad S.S. and Huntress W.T. Astrophys. J. Supp1., 43, 1-35

(180); Astrophys. J., 239, 151-165, (1980).

Brown, R.D. and Rice, E., Phil. Trans. Roy. Soc, 303, 523-533

(1981).

Graede1, T.E., Langer, W.D. and Frerking, M.A., (1982).

3. Brown, R.D. and Rice, E., unpublished calculations.

4. Erickson, N.R., Sne11, R.L., Loren, R.B., Mundy, L. and Plambeck, R.L., Astrophys. J., 245 L83 (1981).

5. Matthews, H.E., Irvine, W.M., Friberg, P., Brown, R.D. and Godfrey, P.D., Nature, 310 125-126 (1984).

6. See for example: Miller, S.L. and Orge1, L.E. "The Origins of Life on the Earth". (Prentice-Ha11, 1974).

7. Brown, R.D. Godfrey,P.D., Storey, J.W.V., Bassez, M.P., Robinson, B.J., Batchelor, R.A., McCulloch, M.G., Rydbeck, O.E.H. and Hjalmasson, A.G., MNRAS, 186, 5P-8P (1979).

8. Hollis, J.M. Snyder, L.E. Suenram, R.D. and Lovas, F.J. Ap. J, 241, 1001-1006, (1980).

9. Drake, F.D., Cohen, C., Brown, R.D., et a1, unpublished. 
10. Godfrey, P.D., Brown, R.D., Storey, J.W.V.\& Robinson, B.J., unpublished.

11. This volume, p. 185-197.

12. Anders, E., Hajatsu, R. and Studier, M.J., Science, 182, 781-790 (1973).

13. Hartman, W.K., Astrophys. \& Space Sci., 17, 48-64 (1972).

14. Akabori, S., Science (Japan), 25, 54 (1955); Akabori, S., Okama, K and Sato, M., Bu11. chem. Soc. Japan, 29, 608 (1956); 30, 937 (1957). 